Research Article

\title{
Performance of RC Beams with Embedded Steel Trusses Using Nonlinear FEM Analysis
}

\author{
Mohammed Arafa (D), Mamoun A. Alqedra, and Ragheb Salim \\ Department of Civil Engineering, The Islamic University of Gaza, Gaza, State of Palestine \\ Correspondence should be addressed to Mohammed Arafa; marafa@iugaza.edu.ps
}

Received 15 October 2018; Revised 20 November 2018; Accepted 26 November 2018; Published 13 December 2018

Academic Editor: Hugo C. Biscaia

Copyright (C) 2018 Mohammed Arafa et al. This is an open access article distributed under the Creative Commons Attribution License, which permits unrestricted use, distribution, and reproduction in any medium, provided the original work is properly cited.

\begin{abstract}
The current study investigates the shear performance of reinforced concrete (RC) beams with embedded steel trusses at small shear span to depth ratios $a / d$ using nonlinear finite element $(\mathrm{FE})$ model. Twenty-one (FE) models have been built using ABAQUS software to investigate the effect of different $a / d$ ratios and web reinforcement on the shear performance and failure load of RC beams with embedded steel trusses. This research focuses on obtaining failure loads, failure modes, crack propagation, and midspan deflection from the developed FE models. The numerical results indicated that, using RC beams with embedded truss with different $a / d$ ratios increased significantly the ultimate shear strength compared with the common RC beams. Furthermore, the numerical results confirmed that embedment of steel trusses in RC beams would significantly improve the structural behavior of RC beams at different $a / d$ ratios. In addition, the results indicated that the shear reinforcement has a small effect on failure and midspan deflection of RC beams with embedded angle trusses at different $a / d$ ratios.
\end{abstract}

\section{Introduction}

When principal tensile stresses of a reinforced concrete beam within the shear region exceed the tensile strength of concrete, diagonal cracks develop in the beam. The brittle nature of concrete causes the collapse to occur shortly after the formation of the first crack [1]. Therefore, the shear failure pattern of the reinforced concrete beam is more critical and unsafe than the flexural failure pattern of the same beam. Thus, in order to improve the shear capacity of concrete beams, the enhancement of the brittle and poor performance of concrete under tension has been proposed and studied in [2].

Many researches have been conducted to enhance the shear strength of reinforced concrete beams through using prestressed concrete, high-strength concrete, steel fiber concrete, ultrahigh performance concrete, and high-strength steel. Nevertheless, these enhancing measures need complex construction technology and special materials. Another technique to enhance shear and flexure strength of reinforced concrete beams is to adopt prefabricated steel trusses embedded in cast-in-place concrete beams, which has advantages of being constructed rapidly and easily [3].

Typical RC beams in which the reinforcement is the steel truss have been used around the world. Differently from common reinforced concrete beams, the steel trusses can carry their own weight and the weight of slabs and fresh concrete without any temporary support during the assembly stage; after that, when concrete develops its own strength, they can collaborate with the cast-in-place concrete. Nowadays, interest for this technology is growing up, mainly because of some advantages it provides with respect to the common reinforced concrete beams. However, neither in the current American nor in the European codes there are specific regulations for this type of reinforced concrete beam $[4,5]$.

The experimental methods were considered very useful in building up knowledge regarding the mechanical behavior of reinforced concrete beams embedded with steel trusses. However, the use of numerical models assists in obtaining a good understanding of the behavior at lower costs and less time. Quaranta et al. [6] developed mechanical models and 
verification principles to be applied in designing of concrete beams reinforced with embedded steel truss subject to static loads.

Zhang et al. [3] carried out experimental and theoretical research to study the performance of reinforced concrete beams using embedded steel trusses. The experimental investigation comprised testing beams with small shear spanto-depth ratios to study their structural performance and ultimate shear capacity. The results indicated that the embedded steel angle truss as additional horizontal reinforcement represents the optimum arrangement for an embedded steel truss in order to improve the shear performance of an RC beam. Furthermore, the experimental results showed that embedding steel trusses in reinforced concrete beams would significantly enhance the structural performance of reinforced concrete beams in shear failure.

Tesser and Scotta [7] investigated the flexural and shear capacity of RC beams having embedded steel truss. The shear and flexural strengths of these beams at several depths, widths, and transverse reinforcement inclination were studied through the experiments. The modes of failure of these beams were investigated with a focus on the crack patterns and the interaction between concrete cast at different times.

Trentadue et al. [8] developed an analytical approach to estimate the critical elastic moment in order to compute the final design lateral-torsional buckling resistance moment in special truss-reinforced composite steel-concrete beams. Furthermore, an analytical method for prediction of the shear resistance of precast composite beams is proposed in [4].

The suggested analytical model was developed in $[9,10]$, based on an experimental program carried out on a threepoint bending tests of hybrid steel trussed concrete beams designed in order to attain a shear failure. Furthermore, the proposed analytical model was supported by the results of the finite element modelling available in the literature tests. Further and in order to study the steel truss-concrete stress transfer mechanism in the truss-reinforced composite steelconcrete beams, a three-dimensional (3D) nonlinear finite element model was developed in [11-13].

Chisari and Amadio [10] carried out an experimental program comprising laboratory and numerical investigation on shear performance of reinforced concrete-encased steel joist beams based on a preliminary test program. Numerical models using ABAQUS package were established, and several steel-concrete patterns were applied for the bottom steel plate. Based on the carried out experimental program, an analytical model is developed to predict the shear capacity of these structural elements.

Monaco [5] studied the shear behavior of the hybrid steel trussed-concrete beams, which is the study aimed at investigating the shear response and the stress transfer mechanism between the steel members and the surrounding concrete using nonlinear FE models.

Composite beams constituted by a concrete-encased steel truss welded to a continuous steel plate are analyzed using a nonlinear finite element formulation based on Newmark's classical model in [14].
In this study, non-linear finite element analysis models for reinforced concrete beams with embedded steel trusses will be developed. ABAQUS, a finite element software package [15], will be used to study the mechanical behavior of reinforced concrete beams with embedded steel trusses (HSTCB) having different shear span-depth a/d ratios. Moreover, the verified finite element model was used to study the effect shear reinforcement on shear behavior of studied beams.

\section{Modelling of RC Beams with Embedded Steel Truss}

The experimental investigation of [3] was used to verify the developed FE model for the reinforced concrete beam using embedded steel truss using ABAQUS software. The control beam is a simply supported beam that had a rectangular cross section of $200 \mathrm{~mm} \times 300 \mathrm{~mm}$. The beam had three smooth steel bars with $22 \mathrm{~mm}$ diameter in the bottom, and two smooth steel bars with $16 \mathrm{~mm}$ diameter in the top of the beam as a longitudinal reinforcement. The stirrups consist of $8 \mathrm{~mm}$ diameter bars spaced at $150 \mathrm{~mm}$ (Figure 1).

In the strengthened beam, the control beam was reinforced with an embedded steel truss. This strengthening technique is called hybrid steel trussed concrete beams (HSTCBs). The embedded steel truss consists of $40 \times$ $40 \times 4 \mathrm{~mm}$ smooth steel angles as upper and lower cords, and $30 \times 30 \times 3 \mathrm{~mm}$ smooth steel angles as struts as shown in Figure 2.

2.1. Material Properties and Models. The material properties of the steel reinforcement, concrete, and embedded steel truss that are used in the analysis are according to the experimental materials of the investigation of [3]. The yield stresses for the reinforcement with the diameters of 8,16 , and $22 \mathrm{~mm}$ were 363,378 , and $393 \mathrm{MPa}$, respectively. While for the embedded truss, the yield stress was $345 \mathrm{MPa}$. Young's modulus was $200 \mathrm{GPa}$, and Poisson's ratio was assumed to be 0.3 .

An elastic-plastic constitutive relationship with strain hardening is assumed for reinforcing steel and embedded steel truss. This model generally yields acceptable results for the response prediction of RC members $[16,17]$.

The concrete compressive strengths were 41.5 and 40.4 MPa for the control beam and the strengthened beam, respectively while the tensile strength for both beams was 4.0 MPa and Young's modulus was $34 \mathrm{GPa}$.

The embedded steel reinforcement model has been used to simulate the reinforced steel and embedded truss. This method of modelling the steel reinforcement solves the mesh restriction problem that appears in discrete and smeared modelling of reinforcement, by evaluation of stiffness of reinforcement elements separately from the concrete elements. This method provides a perfect bond between the host element (concrete) and the slave element (steel rebar and embedded truss). Moreover, in this method, the displacement of steel bars and embedded truss will be compatible with the displacement of the surrounding concrete 


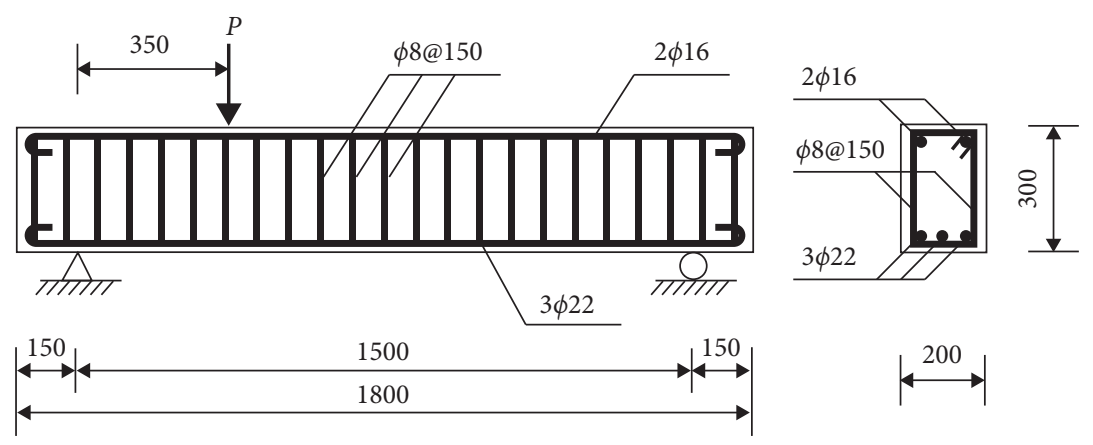

Figure 1: Profile and cross section details of the control beam [3].
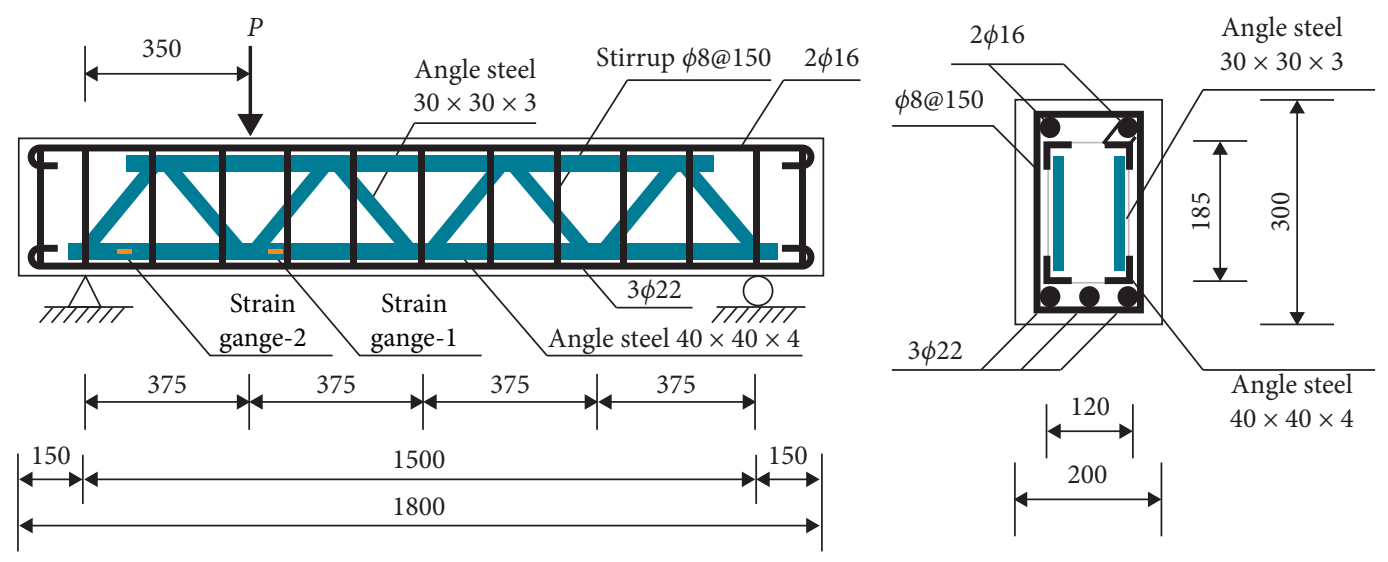

Figure 2: Profile and cross section details of the strengthened beam [3].

elements. The embedded method is very useful when used in complex models. However, this model increases the number of nodes and the degrees of freedom in the model; as a result, it requires more run time and increases the computational cost.

According to ACI Committee 318 [18], the strain of concrete $\varepsilon_{\mathrm{o}}$ at peak compressive stress is 0.003 . A representative value is used in the analysis is 0.003 . Poisson's ratio of concrete under uniaxial compressive stress ranges from about $0.15-0.22$ [19]. In this study, the average value of Poisson's ratio with 0.19 was adopted.

The concrete damaged plasticity model (CDP) was used to simulate the concrete behavior. This method represents an adaptation of the Drucker-Prager criterion, and it accounts for various evolutions of strength under tension and compression. Table 1 presents the recommended CDP values model under compound stress [15].

2.2. Finite Element Mesh. ABAQUS provides different meshing techniques. For plain concrete, a structured mesh is selected, and for the embedded truss, multiple meshes are selected. The mesh element for concrete and embedded truss is a three-dimensional solid, which is called C3D8R. A 2node beam element in three dimensions with linear interpolation formulations B31 is used for the rebar elements. The mesh model of concrete and embedded truss and reinforcement steel are presented in Figures 3 and 4.
TABLE 1: Parameters of the CDP model under compound stress [15].

\begin{tabular}{lc}
\hline Parameter name & Value \\
\hline Dilation angle & 31 \\
Flow potential eccentricity & 0.1 \\
Biaxial/uniaxial compression plastic strain ratio & 1.12 \\
Invariant stress ratio & 0.667 \\
Viscosity & 0 \\
\hline
\end{tabular}

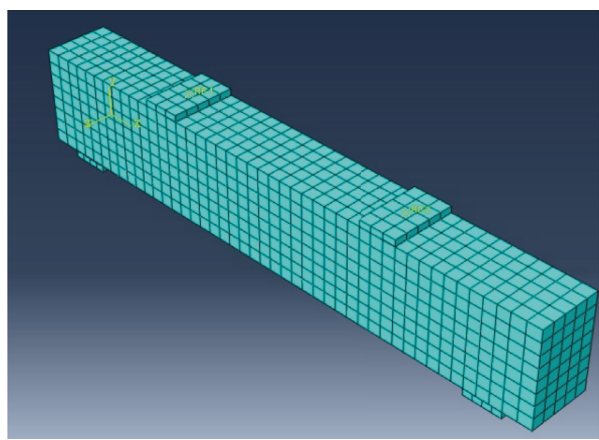

Figure 3: Concrete meshed Model.

2.3. Comparison between the Developed FE Model and Experimental Results. For any reinforced concrete beam analysis, load-deflection behavior is considered as the key response of the structural behavior [20]. In the experimental 


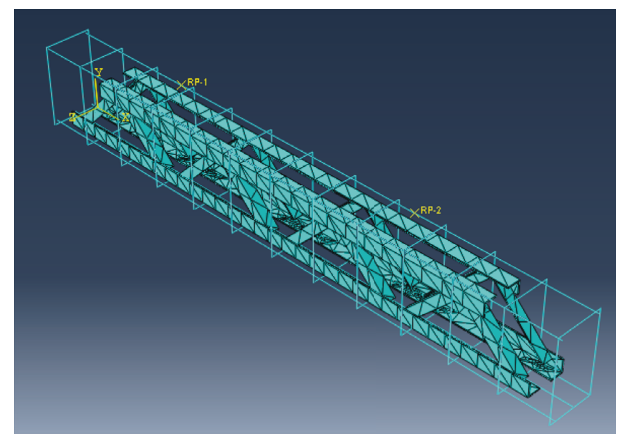

Figure 4: Modelling of the reinforcement steel and embedded truss.

test, the strain gauges were arranged at the critical locations of the reinforcement and the steel angle truss. These gauges measure strain development of steel with the loading process and determine the effects of the embedded steel angle truss on the shear mechanical performances of common reinforced concrete beams. For the analysis of RC beam reinforced with embedded steel truss (HSTCB) investigated in [3], the analysis result shows that the failure patterns of the beam have shear-flexure failure characteristics. The load at failure is $510 \mathrm{kN}$, and the corresponding deflection is $5 \mathrm{~mm}$. The deflected shape at failure for the beam is shown in Figure 5. A comparison of the load-deflection response between the FEA and the test results for the control beam is shown in Figure 6.

The failure load predicted by ABAQUS is $2 \%$ higher than the failure load obtained from the test results, and the midspan deflection at failure which is predicted by the FE analysis is $8 \%$ less than the midspan deflection obtained from the experimental results.

As shown in Figure 2, two strain gauges are installed on the rod of steel truss, and the comparisons between strain curves at gauges 1 and 2 are shown in Figures 7 and 8. These curves indicated that the strain curves obtained from the finite element analysis agree well with the experimental data for the RC beam reinforced with embedded steel truss.

\section{Behavior of RC Beams with Embedded Steel Truss}

To evaluate the effect of the $a / d$ ratio on the behavior of the reinforced concrete beam with embedded steel truss, twentyone beam models with different $a / d$ ratios ranging from 1 to 2.5 with and without shear reinforcement (stirrups) were analyzed using the verified FE model. The different $a / d$ ratios were attained by changing the distance between the loading points $(a)$ as shown in Figure 9.

\subsection{Failure Loads and Load-Deflection Response.} Compared to the control beams, the ultimate load-carrying capacity of RC beams using embedded steel trusses is increased by $66 \%$. Furthermore, comparison between RC beams with $a / d=1$ exhibited the highest increase in ultimate shear strength that exceeds the value of $98 \%$ over RC beams with $a / d=2.5$. For all RC control beams with different $a / d$

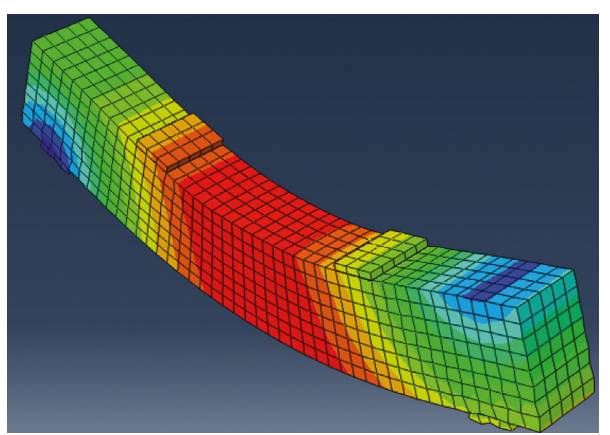

FIGURE 5: The deflected shape at failure for the embedded steel truss RC beam.

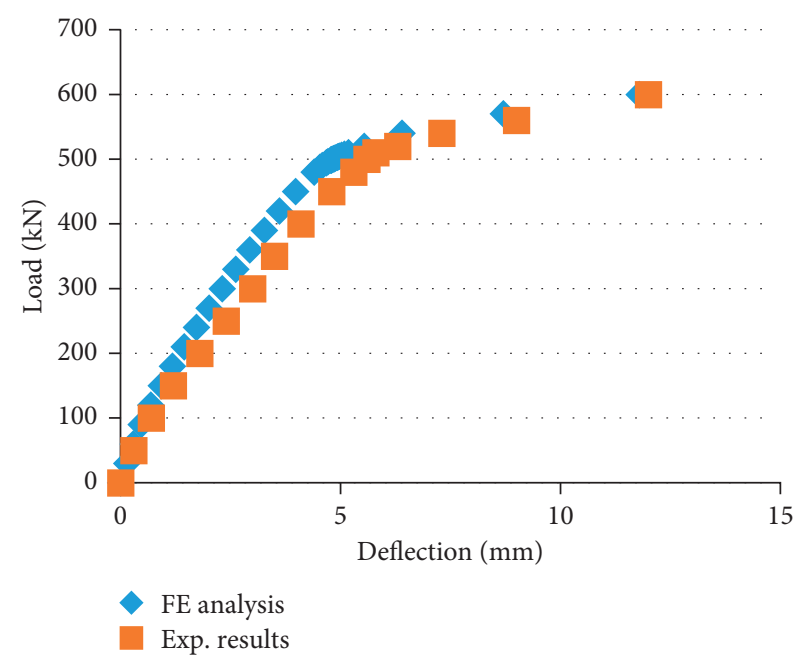

FIGURE 6: Load-deflection response of the embedded steel truss RC beam.

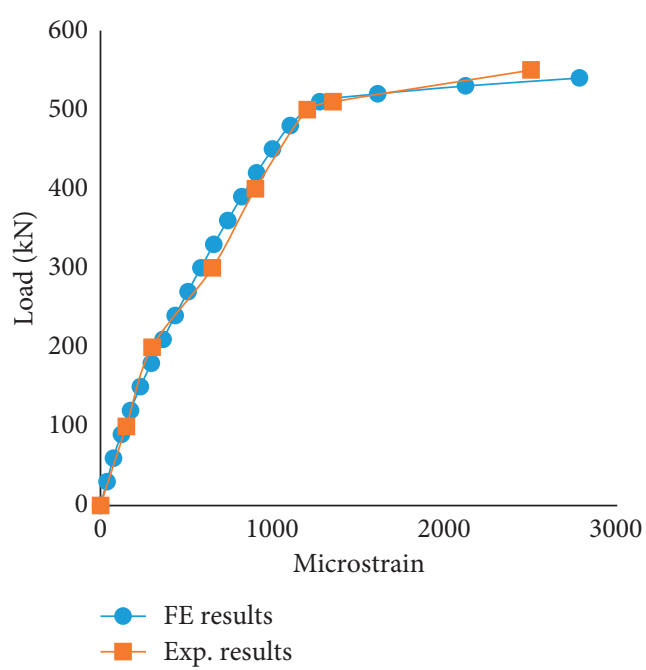

FIGURE 7: Strain curve (strain gauge 1) of steel truss.

ratios, a fixed reinforced steel content of $2.12 \%$ was used, while the steel content of $3.25 \%$ was used in all RC beams with embedded steel trusses.

To verify the numerical results, the ultimate shear strengths of RC control beams and RC beams with 


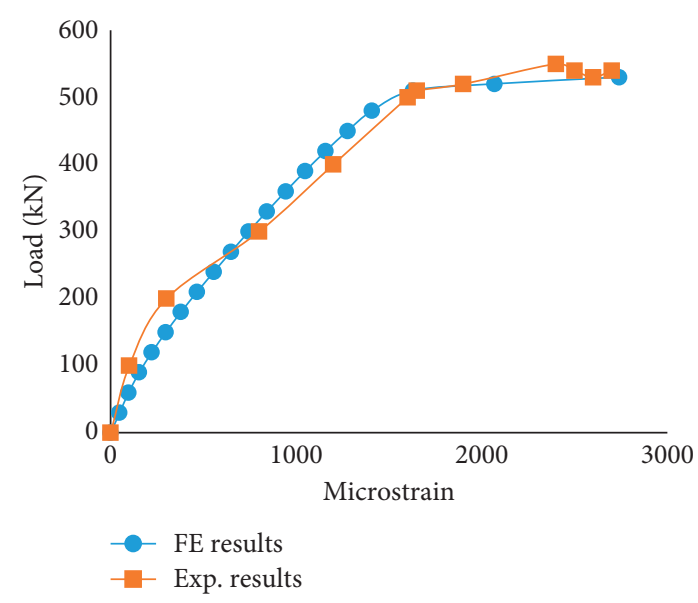

FIgURE 8: Strain curve (strain gauge 2) of steel truss.

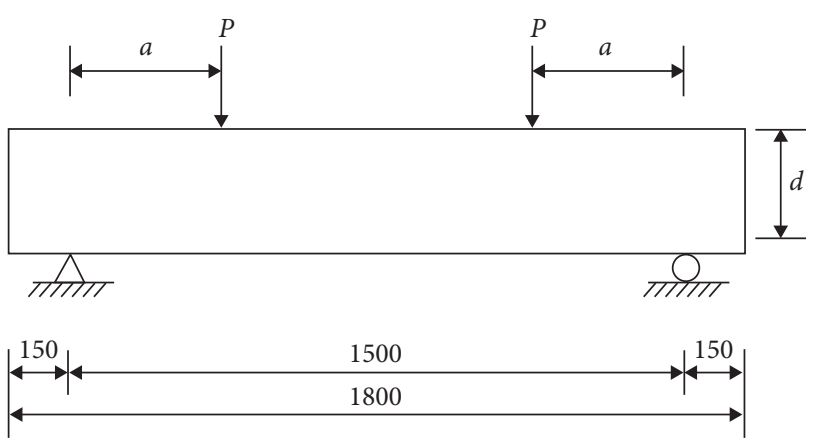

Figure 9: Shear span to depth ratio $a / d$.

embedded steel trusses were calculated according to the analytical model derived and used by Zhang et al. [3].

Comparison between the calculated and numerical ultimate load-carrying capacity of RC beams is presented in Table 2.

Figure 10 shows the deflection of HSTCB with shear reinforcement at different $a / d$ ratios. It shows that the deflection increases with increasing $a / d$ ratios for all beams. The RC beams with embedded steel truss with $a / d$ ratio $=1$ also shows a maximum ultimate failure load of $780 \mathrm{kN}$, which is $166 \%$ higher than the control beam failure load.

3.2. Stress of Embedded Steel Truss. Von Mises stress was used to describe the distribution of stress, and color in each mesh showed the stress value. The stress increases when the color turns from blue to red. The von Mises stress of embedded steel truss is shown in Figure 11. The maximum von Mises stress, $348 \mathrm{MPa}$, appears in the bottom of the central region of the embedded steel truss, around the supports and around the applying loads. At the diagonal steel angles, high stress also appears changing from $217 \mathrm{MPa}$ to $295 \mathrm{MPa}$.

\subsection{Crack Pattern and Failure Modes}

3.3.1. Control Beams. The control RC beams without embedded steel angle trusses with different $a / d$ ratios between 1
TABLE 2: Comparison between the calculated and FE load-carrying capacity of RC beams.

\begin{tabular}{lcccc}
\hline \multicolumn{2}{c}{ a/d } & \multicolumn{2}{c}{ Control beam (kN) } & \multicolumn{2}{c}{$\begin{array}{c}\text { Beams with embedded truss } \\
\text { reinf. HSTCB (kN) }\end{array}$} \\
& FEM & Analytical model [3] & FEM & Analytical model [3] \\
\hline 1 & 480 & 475.9 & 780 & 745.5 \\
1.25 & 420 & 406.5 & 650 & 612.9 \\
1.5 & 365 & 354.1 & 550 & 522.2 \\
1.75 & 300 & 285.4 & 475 & 448.5 \\
2 & 270 & 251.1 & 400 & 391.8 \\
2.25 & 235 & 223.9 & 365 & 347.0 \\
2.5 & 217 & 201.9 & 340 & 311.0 \\
\hline
\end{tabular}

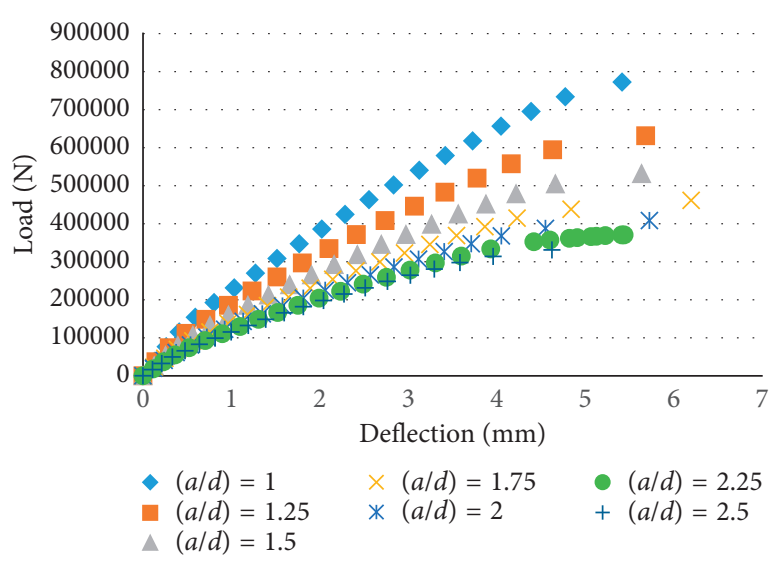

FIgURE 10: Load-deflection relationship for RC beams using embedded steel truss.

and 2 exhibited a similar sequence of crack development. All control beams failed in shear. Diagonal cracks began to form in the region of the beam's shear span and then continued to develop and propagate toward the loading point until the failure. For beams with $a / d=2$, few hairline flexural cracks were observed. For the two control beams with $a / d 2.25$ and 2.5 , flexural cracks formed in the midspan region between the two loading points and continued to develop until failure. Flexural failure of these two beams may occur due to the distance between the two loading points, and this distance is less than one-third clear span, and according to ASTM C78, 2015, this test can be considered as the flexural test. Figure 12 shows the modes of failure of control beams with $a / d$ ratios between 1 and 2.5 .

3.3.2. Beam with Embedded Truss HSTCB. RC beams with steel truss HSTCB and having a/d ratios between 1 and 2.5 were analyzed using the developed FE model. For the RC beams with $a / d$ ratios between 1 and 2 , flexural cracks were formed in the bottom of the central region of the beam and continued to develop and elongate toward the midheight of the beams. Then, diagonal shear cracks began to form in the critical shear span regions followed by the appearance of the main diagonal cracks. Flexural cracks retain their length and width until failure. The two RC beams with embedded steel truss having $a / d$ ratios 2.25 and 2.5 showed a flexural failure 


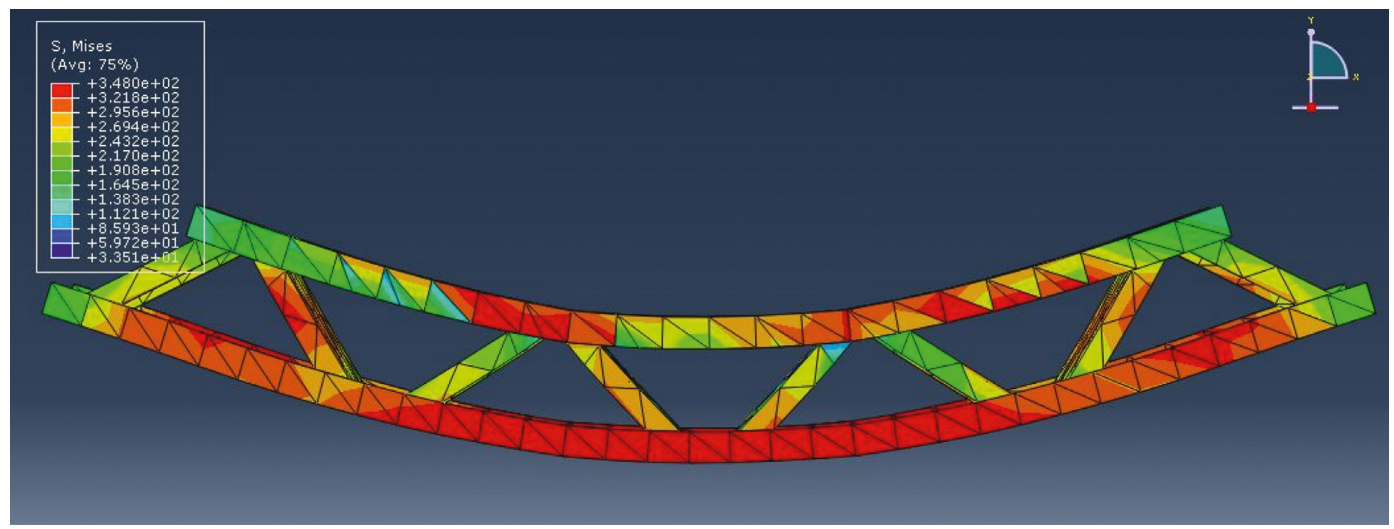

FiguRE 11: von Mises stress of embedded steel truss.

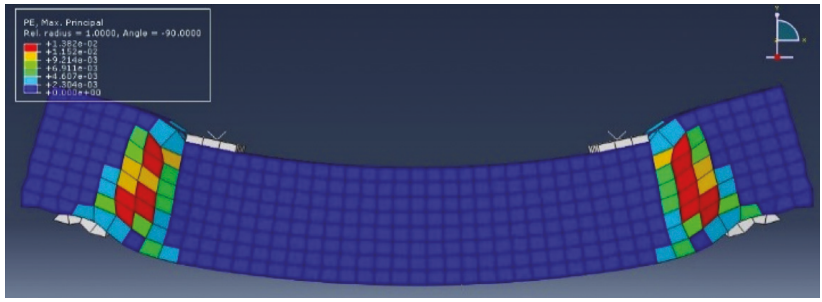

(a)

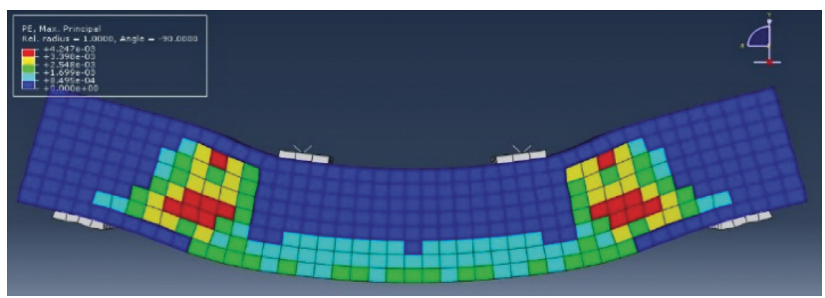

(c)

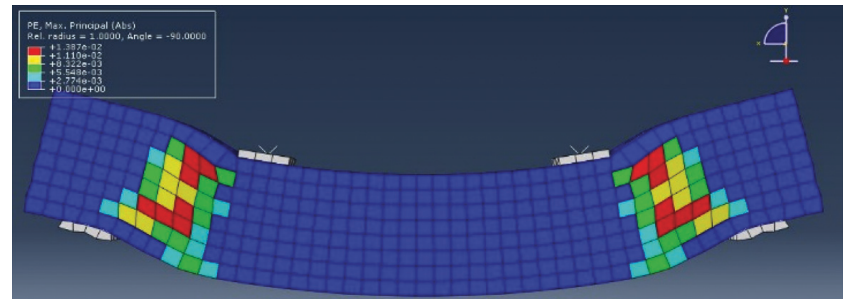

(b)

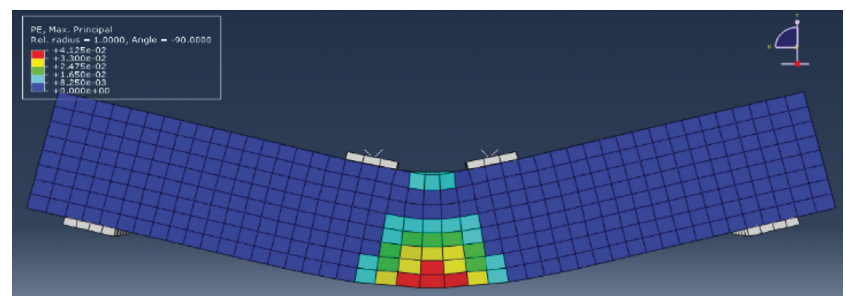

(d)

Figure 12: Failure modes of the control beams with different $a / d$ ratios between 1 and 2.5. (a) $a / d=1$. (b) $a / d=1.5$. (c) $a / d=2$. (d) $a / d=2.5$.

pattern due to the distance between the two loading points. Figure 13 shows the modes of failure of RC beams using steel angle truss and stirrups reinforcement with $a / d$ ratios between 1 and 2.5 .

\subsection{Effect of Shear Reinforcement on the Crack Pattern and} Failure Modes. Table 3 shows the comparison of ultimate load-carrying capacity of HSTC beams with and without shear reinforcement (stirrups). As seen from the table, web reinforcements (stirrups) have a small effect on the ultimate load-carrying capacity of HSTC beams.

RC beams with embedded steel truss HSTCB without shear reinforcement had almost the same behavior and failure pattern of the RC beams with embedded steel truss and with shear reinforcement at different $a / d$ ratios. Figure 14 shows the modes of failure of RC beams using steel angle truss without web reinforcement with different $a / d$ ratios.

\section{Conclusion}

According to the numerical results of the $\mathrm{RC}$ beams using embedded steel angle trusses with different $a / d$ ratios, the following conclusion can be recorded:

(1) All control beams with $a / d$ ratios between 1 and 2.5 failed in shear, while RC beams that used embedded steel angle trusses at the same $a / d$ ratios failed by flexural failure.

(2) All RC beams using embedded steel angle trusses with different $a / d$ ratios gave an increase in ultimate shear strength compared to control beams.

(3) For different $a / d$ ratios, all RC beams using embedded steel angle trusses showed reduction in deflection compared with control beams.

(4) In general, the behavior of tested beams is influenced by $a / d$ ratio. It was found that an increase of the $a / d$ ratio from 1 to 2.5 decreased the failure load for 


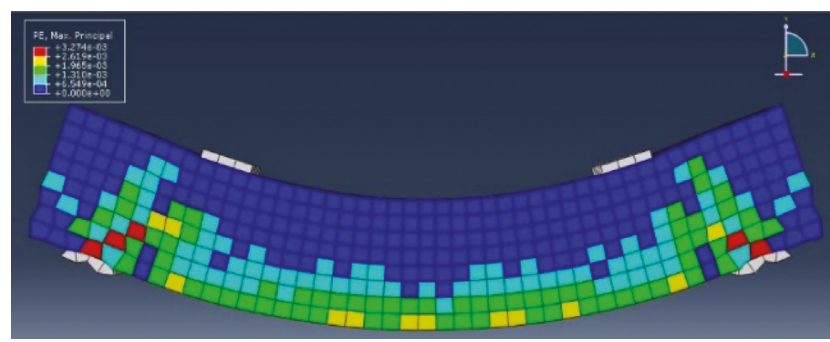

(a)

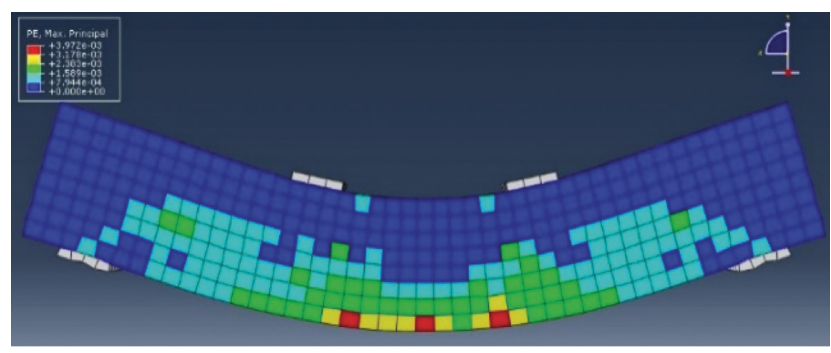

(c)

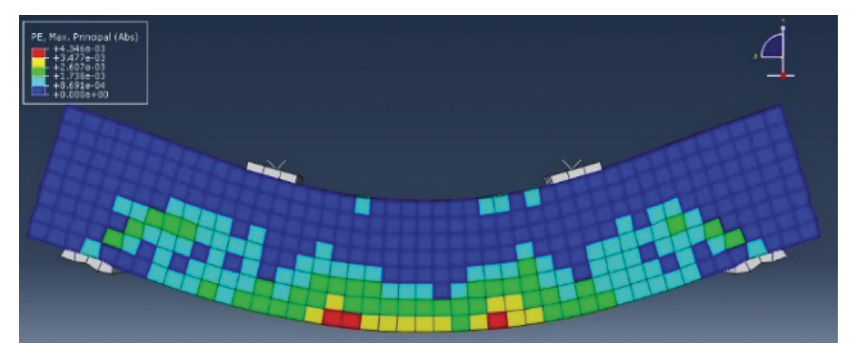

(b)

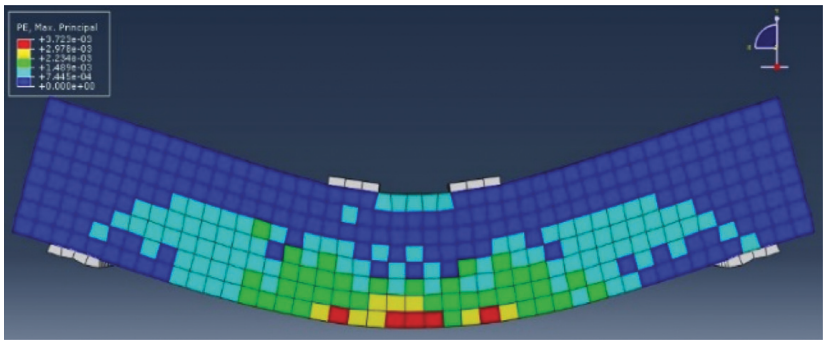

(d)

Figure 13: Modes of failure of RC beams using steel truss with $a / d$ ratios between 1 and 2.5. (a) $a / d=1$. (b) $a / d=1.5$. (c) $a / d=2$. (d) $a / d=2.5$.

TABLE 3: Comparison of ultimate loads carrying capacity of HSTC beams with and without shear reinforcement.

\begin{tabular}{lccc}
\hline$a / d$ & HSTC beams with stirrups $(\mathrm{kN})$ & HSTC beams without stirrups $(\mathrm{kN})$ & \% of reduction \\
\hline 1 & 780 & 720 & 7.7 \\
1.25 & 650 & 585 & 10.0 \\
1.5 & 550 & 498 & 9.5 \\
1.75 & 475 & 425 & 10.5 \\
2 & 400 & 380 & 5.0 \\
2.25 & 365 & 342 & 6.3 \\
2.5 & 340 & 310 & 7.3 \\
\hline
\end{tabular}

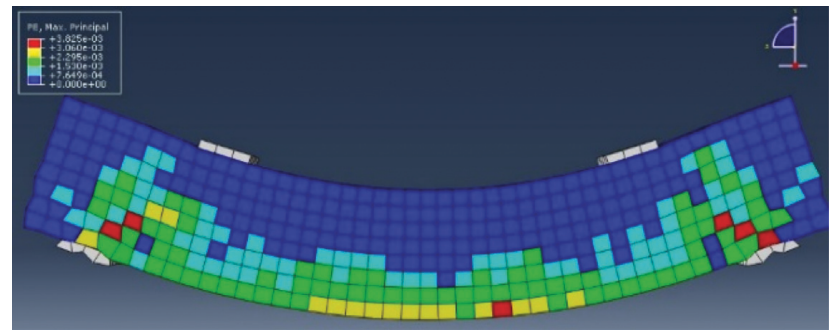

(a)

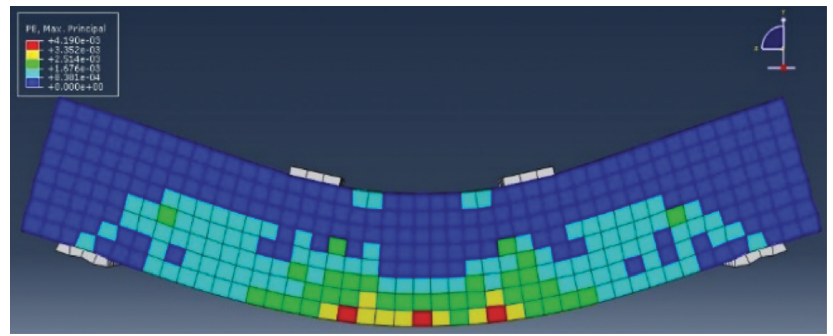

(c)

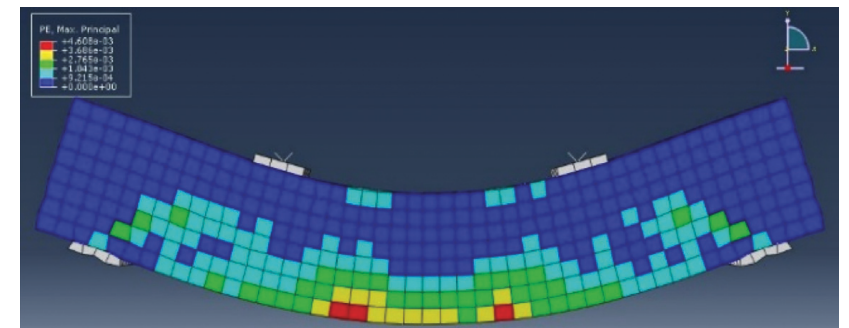

(b)

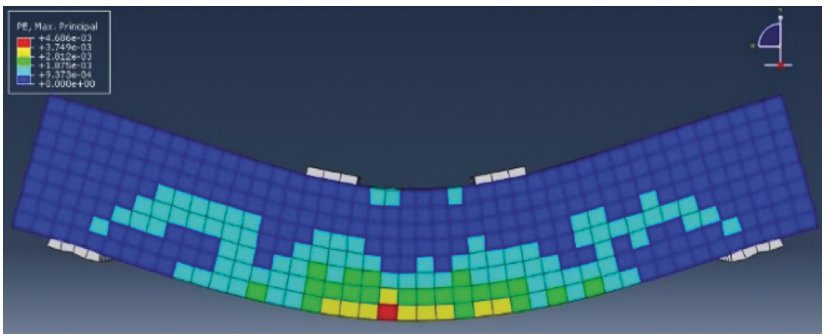

(d)

FIGURE 14: Modes of failure of the RC beams using steel truss without shear reinforcement and having $a / d$ ratios between 1 and 2.5 . (a) $a / d=$ 1. (b) $a / d=1.5$. (c) $a / d=2$. (d) $a / d=2.5$. 
control and embedded steel trusses beams by about $48 \%$ and $45 \%$, respectively.

(5) With the increase in the a/d ratio, the midspan deflection increased.

(6) For RC beams that used embedded steel trusses with different $a / d$ ratios, the shear reinforcement has a small effect on both failure load and crack pattern of beams.

\section{Data Availability}

The data used to support the findings of this study are available from the corresponding author upon request.

\section{Conflicts of Interest}

The authors declare that they have no conflicts of interest.

\section{References}

[1] D. H. Lim and B. H. Oh, "Experimental and theoretical investigation on the shear of steel fibre reinforced concrete beams," Engineering Structures, vol. 21, no. 10, pp. 937-944, 1999.

[2] B. B. Adhikary and H. Mutsuyoshi, "Shear strengthening of reinforced concrete beams using various techniques," Construction and Building Materials, vol. 20, no. 6, pp. 366-373, 2006.

[3] N. Zhang, C. C. Fu, L. Chen, and L. He, "Experimental studies of reinforced concrete beams using embedded steel trusses," ACI Structural Journal, vol. 113, no. 4, 2016.

[4] G. Campione, P. Colajanni, and A. Monaco, "Analytical evaluation of steel-concrete composite trussed beam shear capacity," Materials and Structures, vol. 49, no. 8, pp. 31593176, 2015.

[5] A. Monaco, "Experimental analysis, numerical and analytical modeling of shear strength mechanisms in hybrid steel trussed concrete beams," Ph.D. thesis, Università degli Studi di Palermo, Palermo, PA, Italy, 2014.

[6] G. Quaranta, F. Petrone, G. Marano, and G. MONTI, "Structural design of composite concrete-steel beams with spatial truss reinforcement elements," Asian Journal of Civil Engineering (Building and Housing), vol. 12, no. 2, pp. 155178, 2011.

[7] L. Tesser and R. Scotta, "Flexural and shear capacity of composite steel truss and concrete beams with inferior precast concrete base," Engineering Structures, vol. 49, pp. 135-145, 2013.

[8] F. Trentadue, G. Quaranta, G. Carlo Marano, and G. Monti, "Simplified lateral-torsional buckling analysis in special trussreinforced composite steel-concrete beams," Journal of Structural Engineering, vol. 137, no. 12, pp. 1419-1427, 2011.

[9] A. Cladera and A. R. Marí, "Experimental study on highstrength concrete beams failing in shear," Engineering Structures, vol. 27, no. 10, pp. 1519-1527, 2005.

[10] C. Chisari and C. Amadio, "An experimental, numerical and analytical study of hybrid RC-encased steel joist beams subjected to shear," Engineering Structures, vol. 61, pp. 84-98, 2014.

[11] P. Colajanni, L. La Mendola, M. Latour, A. Monaco, and G. Rizzano, "FEM analysis of push-out test response of hybrid steel trussed concrete beams (HSTCBs)," Journal of Constructional Steel Research, vol. 111, pp. 88-102, 2015.
[12] P. Colajanni, L. La Mendola, and A. Monaco, "Stress transfer mechanism investigation in hybrid steel trussed-concrete beams by push-out tests," Journal of Constructional Steel Research, vol. 95, pp. 56-70, 2014.

[13] P. Colajanni, L. La Mendola, and A. Monaco, "Stiffness and strength of composite truss beam to R.C. column connection in MRFs," Journal of Constructional Steel Research, vol. 113, pp. 86-100, 2015.

[14] N. Tullini and F. Minghini, "Nonlinear analysis of composite beams with concrete-encased steel truss," Journal of Constructional Steel Research, vol. 91, pp. 1-13, 2013.

[15] M. Smith, ABAQUS/Standard User's Manual, Version 6.9, Simulia, Providence, RI, USA, 2009.

[16] U. Khan, M. A. Al-Osta, and A. Ibrahim, "Modeling shear behavior of reinforced concrete beams strengthened with externally bonded CFRP sheets," Structural Engineering and Mechanics, vol. 61, no. 1, pp. 125-142, 2017.

[17] K. Neale, U. Ebead, H. Abdel Baky, W. Elsayed, and A. Godat, Modelling of Debonding Phenomena in FRP-Strengthened Concrete Beams and Slabs, International Institute for FRP in Construction, Winnipeg, MB, Canada, 2005.

[18] ACI 318, ACI 318-14 Building Code Requirements for Structural Concrete and Commentary (Metric), American Concrete Institute, Miami, FL, USA, 2014.

[19] ASCE, State-of-the-Art Report on Finite Element Analysis of Reinforced Concrete, American Society of Civil Engineers, New York, NY, USA, 1982.

[20] H.-T. Hu, F.-M. Lin, and Y.-Y. Jan, "Nonlinear finite element analysis of reinforced concrete beams strengthened by fiberreinforced plastics," Composite Structures, vol. 63, no. 3-4, pp. 271-281, 2004. 


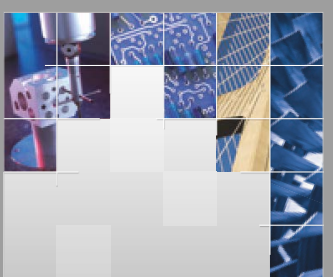

\section{Enfincering}
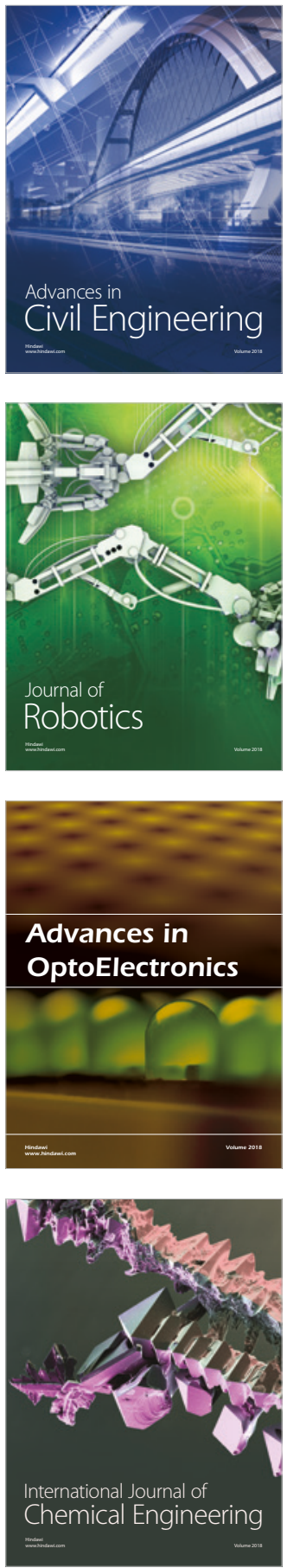

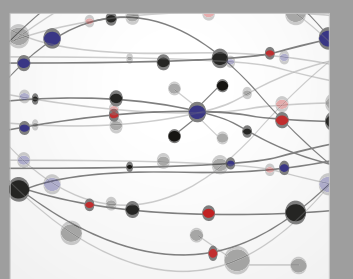

\section{Rotating \\ Machinery}

The Scientific World Journal

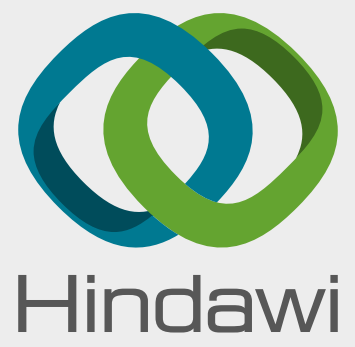

Submit your manuscripts at

www.hindawi.com
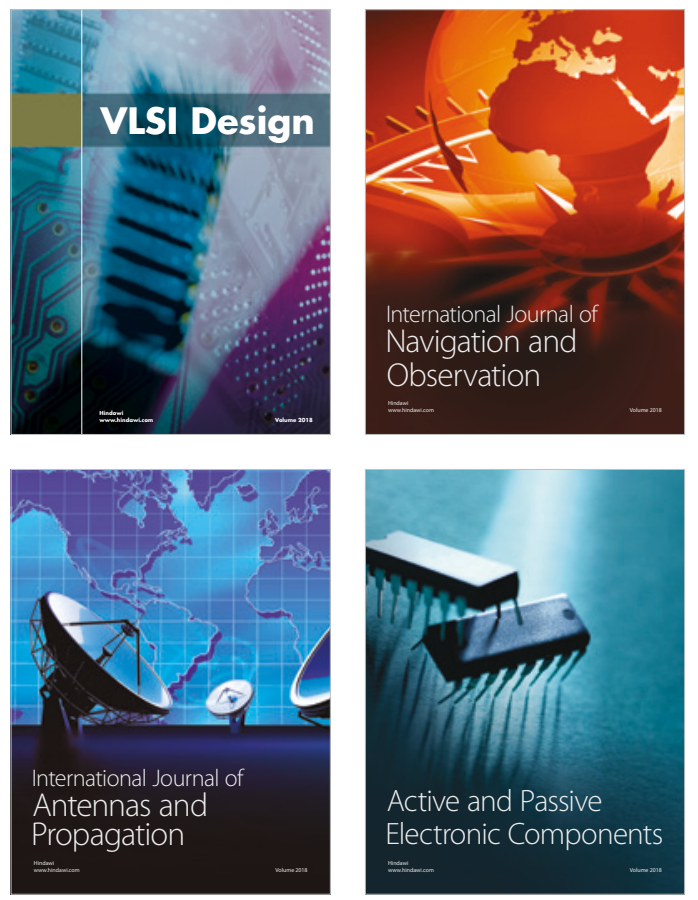
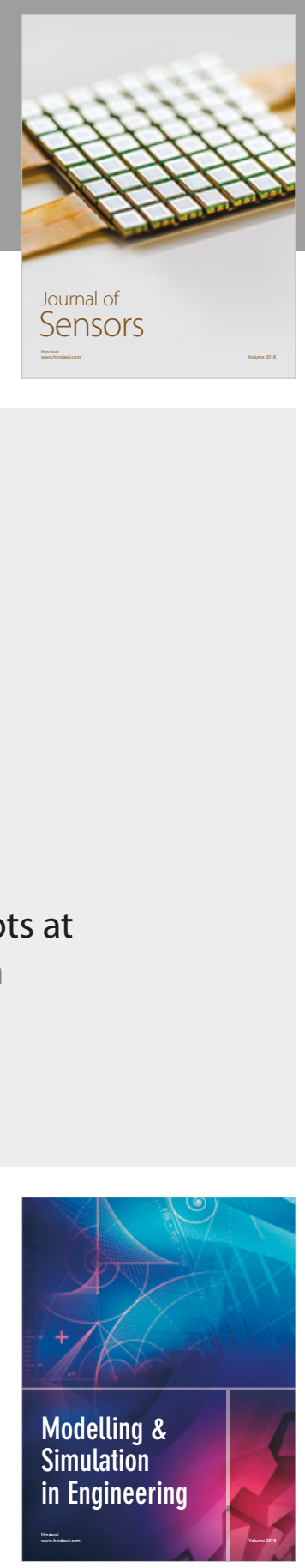

\section{Advances \\ Multimedia}
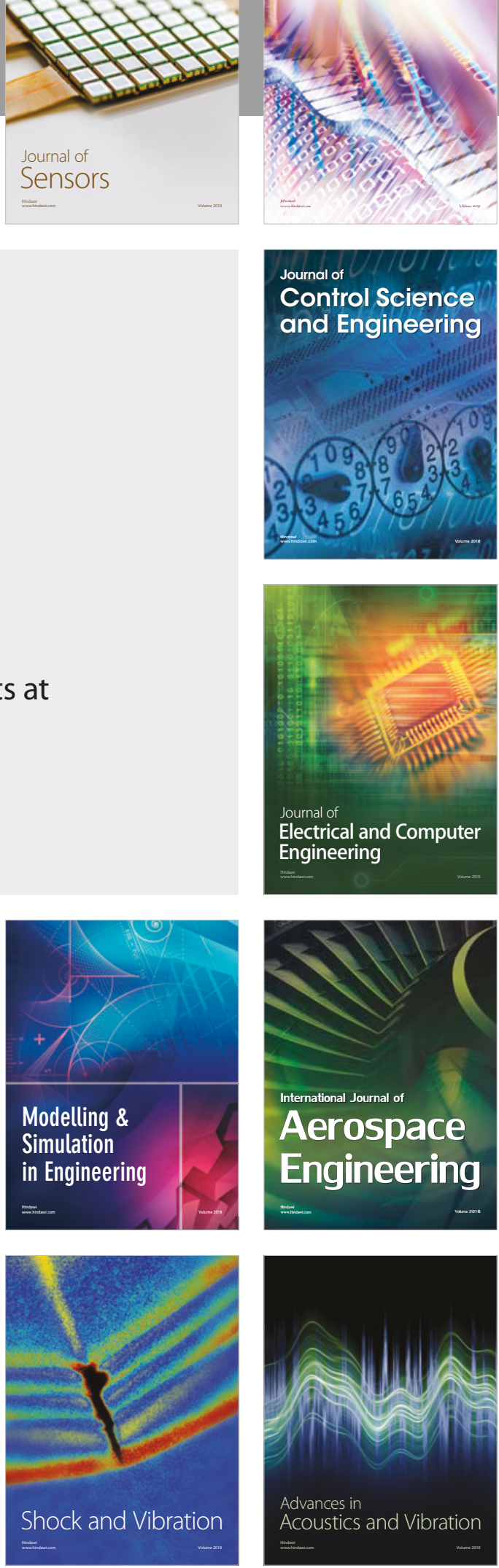